\title{
Failure of regular external ventricular drain exchange to reduce cerebrospinal fluid infection: result of a randomised controlled trial
}

\author{
G K C Wong, W S Poon, S Wai, L M Yu, D Lyon, J M K Lam
}

J Neurol Neurosurg Psychiatry 2002;73:759-761

Background: It is controversial whether regular changes of external ventricular drains can reduce cerebrospinal fluid (CSF) infection.

Objective: To carry out a randomised controlled clinical trial over a two year period to determine whether a regular change of ventricular catheter every five days could reduce CSF infection and improve outcome.

Methods: 103 patients requiring external ventricular drains for more than five days and with no evidence of concurrent CSF infection were studied. The patients were randomised to regular change of ventricular catheter (every five days) and no change unless clinically indicated. Results: The CSF infection rates were $7.8 \%$ for the catheter change group and $3.8 \%$ for the no change group, respectively (rate ratio $=1.80,95 \%$ confidence interval 0.33 to $9.81, p=0.50$ ). No significant difference was found in intensive care unit stay, ward stay, or clinical outcome between the two groups.

Conclusions: Regular changes of ventricular catheter at five day intervals did not reduce the risk of CSF infection. A single external ventricular drain can be employed for as long as clinically indicated.

E xternal ventricular drains are used for intracranial pressure monitoring and temporary cerebrospinal fluid (CSF) drainage, the major complication of their use being CSF infection. The incidence of ventriculostomy related CSF infection has been quoted in previous reports as being between $2.2 \%$ and $10.4 \%{ }^{1-7}$

To reduce catheter associated CSF infection, Mayhall et al,[8] following a prospective epidemiological study, recommended the removal and reinsertion of the catheter at an alternative site if external ventricular drainage was to be continued for more than five days. However, results from a more recent randomised controlled trial conducted by Cobb et al suggested that the routine replacement of central vascular catheters every three days does not prevent infection, [9] while subsequent retrospective analyses of intracranial pressure monitors ${ }^{23} 7^{10}{ }^{11}$ have been inconsistent with respect to infection rates. Thus recommendations about routine changing of ventricular catheters remain controversial. To investigate whether regular changes of external ventricular drainage catheters can decrease the CSF infection rate and improve outcome, we conducted a randomised trial comparing two patient groups, one with regular changes of catheter and the other with no change unless clinically indicated.

\section{METHODS}

\section{Study population}

The study was carried out in two large 1400 bed regional hospitals in Hong Kong. From November 1998 to November 2000, all patients with an external ventricular drain in situ for more than five days were eligible to participate in the study. Patients with known meningitis and uncorrectable coagulopathy were excluded. Informed consent was obtained from patients or their relatives, and the study was approved by the ethics committees of both hospitals.

From our internal audit of CSF infection in the period 1995-1998, the CSF infection rate in patients with a ventricular catheter remaining unchanged for longer than five days was $30 \%$, while in patients with catheter changes at five day intervals it was $8 \%$. Using these historical data to prove our hypothesis that "change of ventricular catheter at five day intervals reduces CSF infection" required a sample size of 49 or a $2 \mathrm{~N}$ of $98\left(\mathrm{p}_{1}=0.3, \mathrm{p}_{2}=0.08, \alpha=0.05\right.$, power $\left.=0.8\right){ }^{12}$

\section{Randomisation}

Patients were randomised into two groups. Group 1 had routine changes of external ventricular drainage catheters every five days during the period for which the use of such drainage was considered clinically necessary. Group 2 had no change of catheters unless clinically indicated because of blockage, the drain remaining in situ and undisturbed throughout its period of use. Randomised group numbers were kept in sealed envelopes and were opened on day 5 for each patient requiring an external ventricular drainage catheter in situ for more than five days.

\section{Catheter change}

The procedure was usually carried out by a neurosurgical resident. The old catheter was removed using aseptic technique. CSF from the catheter was saved for culture and sensitivities.

To prepare for the new insertion on the opposite side, the scalp was cleaned with alcoholic hibitane and aqueous hibitane and then draped. A $3 \mathrm{~cm}$ incision was made anterior to the coronal suture in the mid-pupillary line. A burr hole was made using a craniotomy burr or Hudson's brace. After opening the dura, the ventricular catheter (EDSII, Codman) was inserted, aiming at the foramen of Monro. Its position was confirmed by egress of CSF. The catheter was then tunnelled for around $4 \mathrm{~cm}$. The galea was closed with $2 / 0$ Vicryl and the skin with 3/0 Ethilon. The catheter was anchored with 3/0 Ethilon.

All patients were given prophylactic antibiotic cover with sulbactam/ampicillin (Unasyn) and ceftriaxone (Rocephin) throughout the period of catheter drainage.

\section{Clinical data}

Following randomisation, a research nurse began gathering data. Information collected included age, sex, race, date of admission, diagnosis, underlying disease, all surgical operations, clinical infection, intensive care unit stay, hospital stay, and clinical outcome (using the Glasgow outcome scale). A record was kept of the radiology, microbiology, and blood test results. 
Table 1 Patient characteristics in the randomised groups

\begin{tabular}{|c|c|c|c|}
\hline Variable & $\begin{array}{l}\text { Group } 1 \\
\text { (change) }\end{array}$ & $\begin{array}{l}\text { Group } 2 \\
\text { (no } \\
\text { change) }\end{array}$ & $\mathrm{p}$ Value \\
\hline Number of patients & 51 & 52 & \\
\hline Age (years)* & $55(14)$ & $49(15)$ & 0.051 \\
\hline$M / F$ & $27 / 24$ & $27 / 25$ & 0.918 \\
\hline Indications for EVD (\%) & & & 0.577 \\
\hline Head injury & $9(18)$ & $9(17)$ & \\
\hline Stroke & 39 (77) & $42(81)$ & \\
\hline Others & $3(6)$ & $1(2)$ & \\
\hline Associated craniotomy (\%) & $22(43)$ & $24(46)$ & 0.844 \\
\hline Duration of EVD needed (days) * & $13(7)$ & $11(4)$ & 0.19 \\
\hline Number of EVDs changed* & $2.8(1.0)$ & $\dagger$ & \\
\hline
\end{tabular}

Values are $\mathrm{n}(\%)$ or * mean (SD).

†One needed to be changed because of blockage.

$E V D$, external ventricular drain; $F$, female; $M$, male.

Table 2 Cerebrospinal infection data in the randomised groups

\begin{tabular}{llll}
\hline CSF infection & $\begin{array}{l}\text { Group 1 } \\
\text { (change) }\end{array}$ & $\begin{array}{l}\text { Group 2 (no } \\
\text { change) }\end{array}$ & p Value \\
\hline Number (\%) & $4(7.8 \%)$ & $2(3.8 \%)$ & 0.44 \\
Organisms & & & \\
Coagulase-ve staphylococci & 2 & 0 & \\
MRSA & 2 & 0 & \\
$\quad$ Acinetobacter sp & 0 & 2 & \\
Associated mortality & $3(75 \%)$ & $1(50 \%)$ & \\
\hline
\end{tabular}

CSF, cerebrospinal fluid; MRSA, methicillin resistant Staphylococcus aureus.

\section{Microbiology}

All microbiology specimens were processed in the hospital laboratories. Routine cell counts, differential counts, and Gram stains were done on all specimens. The CSF specimens were cultured in blood agar, chocolate agar, and BHI $+10 \%$ serum broth. MacConkey agar culture was also used if the Gram stain revealed Gram negative rods. CSF was collected by aseptic technique from the drainage catheter every five days or when indicated clinically in both patient groups. If the catheter had already been removed and CSF collection was clinically warranted, a lumbar puncture was done.

The definition of CSF infection was adapted from the Centre for Disease Control guidelines. At least one of the following criteria must be met: (1) the presence of an organism isolated from CSF culture; $(2)$ the presence of fever $\left(>38^{\circ} \mathrm{C}\right)$ in the absence of other recognised causes, with institution of appropriate antimicrobial treatment and any of the following: increased white cell count ( $>50 \%$ polymorphonuclear leucocytes), increased protein, and/or decreased glucose $(<15 \mathrm{~g} / \mathrm{dl})$ in CSF, or organisms visible on CSF Gram stain. All CSF infection within the first three months after ventricular catheter insertion was considered to be catheter related.

\section{Statistical analysis}

The frequency of categorical variables was assessed using a $\chi^{2}$ test or Fisher's exact test. Mean values of quantitative variables were compared with an unpaired $t$ test or the MannWhitney U test. The association between use of external ventricular drainage and infection rates was expressed as a rate ratio. Confidence intervals and probability $(\mathrm{p})$ values were calculated from a Poisson regression analysis. All statistical analyses were done using SAS for Windows version 8.02 (SAS institute Inc, Cary, North Carolina, USA), with the exception of power analysis and trial design, for which PASS 2000 and NCSS 2000 were used.
Table 3 Outcome data in the randomised groups

\begin{tabular}{|c|c|c|c|}
\hline Outcome & $\begin{array}{l}\text { Group } 1 \\
\text { (change) }\end{array}$ & $\begin{array}{l}\text { Group } 2 \text { (no } \\
\text { change) }\end{array}$ & $\mathrm{p}$ Value \\
\hline $\begin{array}{l}\text { ICU stay (days) } \\
\text { Ward stay (days) } \\
3 \text { Month GOS: } \\
\text { favourable } v \\
\text { unfavourable }\end{array}$ & $\begin{array}{l}9(7) \\
22(22) \\
9 \times 42\end{array}$ & $\begin{array}{l}10(9) \\
25(26) \\
14 v 38\end{array}$ & $\begin{array}{l}0.56 \\
0.52 \\
0.42\end{array}$ \\
\hline
\end{tabular}

\section{RESULTS}

\section{Patient characteristics}

In all, 103 eligible patients were included in the study: 51 were randomised to group 1 (change group) and 52 to group 2 (no change group). One patient was wrongly randomised to group 1 and was excluded. Age, sex, disease category, mean duration of external ventricular drainage needed, and other cranial operations performed are listed in table 1. No significant differences in these data were present between the two groups, though there was a trend for patients in group 1 to be somewhat older than those in group $2(p=0.051)$. The number of catheters used in both groups was also charted. The mean number of catheters used in the change group was 2.8 per patient. Only one catheter needed to be changed in the no change group, because of blockage.

\section{CSF infection}

Four patients in group 1 (change group) and two patients in group 2 (no change group) had CSF infection (table 2). In group 1 , the pathogens were coagulase negative staphylococci in two patients and methicillin resistant staphylococci in the other two. In group 2, the pathogens were acinetobacter in both patients. All the bacteria are common in the skin flora of patients in intensive care units.

All infections occurred after day 10-that is, after the second ventricular catheter insertion in the change group. On further review of the profile of the patients with staphylococcal CSF infection, all were stroke patients and only one had had an additional craniotomy. For reference, the days of positive culture in the change group were D17 (at the third catheter), D2 1 (at the forth catheter), D24 (at the fifth catheter), and D54 (after six catheters, CSF obtained by lumbar puncture); the days of positive culture in the no change group were D1 1 and D31.

The higher proportion of CSF infection detected in group 1 $(7.8 \%)$ than in group $2(3.8 \%)$ was not statistically significant (rate ratio $=1.8,95 \%$ confidence interval 0.33 to 9.81 , $\mathrm{p}=0.50)$.

\section{Outcome}

There were no significant differences in intensive care unit stay or ward stay between the two groups $(\mathrm{p}=0.56$ and $\mathrm{p}=0.52$, respectively) (table 3 ). Forty two patients in group $\mathrm{l}$ $(82 \%)$ and $38(73 \%)$ in group 2 had an unfavourable outcome at three months according to the Glasgow outcome scale. This difference was not significant $(p=0.42)$. All patients with CSF infection except one had an unfavourable outcome (four deaths and one severe disability).

\section{DISCUSSION}

Mayhall's recommendation[8] that ventricular catheters should be changed regularly to reduce CSF infection has been challenged by various investigators. In 1993, Winfield et al noted that the CSF infection incidence before day 5 was similar to after day 5 up to the second week. ${ }^{7}$ Using data obtained from the traumatic coma databank and the Medical College of 
Virginia neurocore databank, Holloway et al reviewed the incidence of ventriculitis in 584 patients with severe head injury. ${ }^{2}$ They found non-linear relations between the duration of ventricular catheter placement and ventriculitis. The risk of infection increased during the first 10 days, but after that, infection became unlikely. The infection rate in patients whose catheters were replaced in less than five days was not lower than in patients whose catheters were exchanged at intervals longer than five days. These investigators found no support for the routine exchange of catheters when intracranial pressure monitoring was required for more than five days. The weakness of their recommendation, as in most series, lay in the retrospective and observational nature of the studies.

The randomised study described here shows that routinely changing the ventricular catheter does not reduce the incidence of CSF infection. This finding is in line with the hypothesis that CSF infection is the result of contamination during the procedure of catheter placement; indeed, our data suggest that there may be a small increase in the risk of infection with a policy of routine catheter change $(7.8 \%$ versus $3.8 \%)$. Using the data of the current study for sample size calculation, it can be shown that a definitive study proving that catheter change does harm to the patient would require 1325 subjects $(2 \mathrm{~N})$. This is unlikely to be ethically justifiable or necessary. The practice of regular changes of ventricular catheter as suggested by Mayhall ${ }^{8}$ should no longer be recommended because of the lack of clinical benefit. We recommend first, that the catheter should be inserted under aseptic technique and should be kept in situ unless a change is clinically indicated (for example, if there is evidence of CSF infection or catheter malfunction); and second, that the catheter should be removed as soon as it is no longer clinically indicated.

The catheter related CSF infection rates of 3.8\% and $7.8 \%$ for the no change group and change group, respectively, in our study are within recently reported ranges. ${ }^{1-7}$ In fact, our no change group had a lower rate than in most contemporary series. Four of the pathogens were staphylococci and two were acinetobacter. The spectrum of pathogens was similar to that in other series. ${ }^{14781314}$ The outcome of these catheter associated CSF infections was mostly poor.

Prophylactic antibiotic cover was used during the period of catheter placement, based on the results of a randomised controlled trial in our unit, ${ }^{4}$ which showed the greater efficacy of prophylactic antibiotic treatment over periprocedural antibiotics in reducing CSF infection in neurosurgical patients. A subsequent retrospective analysis by Alleyne et al and Rebuck et al has questioned the effect of prophylactic antibiotics ${ }^{15}$ but the weakness of those studies lay in the choice of antibiotics and the retrospective observational nature of the analysis. Further antibiotic studies are warranted to ascertain, in a modern setting, whether the benefits of prophylactic antibiotic treatment outweigh the risks of opportunistic infection.

\section{Conclusions}

Routinely changing exernal ventricular drainage catheters at five day intervals did not reduce the risk of CSF infection and did not improve the clinical outcome. A single ventricular catheter can be used for as long as clinically indicated unless a change is necessary because of CSF infection or catheter malfunction.

\section{Authors' affiliations}

G K C Wong, W S Poon, S Wai, J M K Lam, Division of Neurosurgery, Department of Surgery, Prince of Wales Hospital, The Chinese University of Hong Kong, Hong Kong

D Lyon, Department of Microbiology, Prince of Wales Hospital

L M Yu, Centre for Clinical Trials and Epidemiological Research, Chinese

University of Hong Kong

Competing interests: none declared

Correspondence to: Dr W S Poon, Division of Neurosurgery, Department of Surgery, Prince of Wales Hospital, The Chinese University of Hong Kong, Shatin, Hong Kong; wpoon@cuhk.edu.hk

Received 5 November 2001

In revised form 22 July 2002

Accepted 30 August 2002

\section{REFERENCES}

1 Alleyne $\mathbf{C H}$, Hassan M, Zabramski. The efficacy and cost of prophylactic and periprocedural antibiotics in patients with external ventricular drains. Neurosurgery 2000;47:1124-9.

2 Holloway KL, Barnes T, Choi S, et al. Ventriculostomy infections: the effects of monitoring duration and catheter exchange in 584 patients. J Neurosurg 1996;85:419-26.

3 Paramore CG, Turner DA. Relative risks of ventriculostomy infection and morbidity. Acta Neurochir (Wien) 1994; 127:79-84.

4 Poon WS, Ng S, Wai S. CSF antibiotic prophylaxis for neurosurgical patients with ventriculostomy: a randomized study. Acta Neurochir Suppl (Wien) 1998;71:146-8.

5 Rebuck JA, Murry KR, Rhoney DH, et al. Infection related to intracranial pressure monitors in adults: analysis of risk factors and antibiotic prophylaxis. J Neurol Neurosurg Psychiatry 2000;69:381-9.

6 Rossi S, Buzzi F, Paparella A, et al. Complications and safety associated with ICP monitoring: a study of 542 patients. Acta Neurochir Suppl (Wien) 1998:71:91-3.

7 Winfield JA, Rosenthal P, Kanter RK, et al. Duration of intracranial pressure monitoring does not predict daily risk of infective complications. Neurosurgery 1993;33:424-31

8 Mayhall CG, Archer NH, Lamb VA, et al. Ventriculostomy-related infections: a prospective epidemiological study. N Engl J Med 1984:310:553-9.

9 Cobb DK, High PK, Sawyer RG, et al. A controlled trial of scheduled replacement of central venous and pulmonary artery catheters. N Engl J Med 1992;327:1062-8.

10 Rosner MJ, Becker DP. ICP monitoring: complications and associated factors. Clin Neurosurg 1976;23:494-519.

11 Schultz M, Moore K, Foote AW. Bacterial ventriculitis and duration of ventriculostomy catheter insertion. J Neurosci Nurs 1993;25: 158-64. 12 Machin D, Campbell M, Fayers PM, et al, eds. Sample size tables for clinical studies, 2nd ed. Oxford: Blackwell Science, 0000.

13 Aucoin PJ, Kotilainen HR, Gantz NM, et al. Intracranial pressure monitors: epidemiologic study of risk factors and infections. Am J Med 1986;80:369-76.

14 Gaskin PR, StJohn MA, Cave CT, et al. Cerebrospinal fluid shunt infection due to corynebacterium xerosis. J Infect 1994;28:323-5. 